\section{Transient activation of $\beta$-catenin signaling in cutaneous keratinocytes is sufficient to trigger the active growth phase of the hair cycle in mice}

\author{
David Van Mater, ${ }^{1}$ Frank T. Kolligs, ${ }^{2,6}$ \\ Andrzej A. Dlugosz, ${ }^{3,5,7}$ and Eric R. Fearon ${ }^{1,2,4,5,8}$ \\ ${ }^{1}$ Departments of Human Genetics, ${ }^{2}$ Internal Medicine, \\ ${ }^{3}$ Dermatology, and ${ }^{4}$ Pathology, and the ${ }^{5}$ Cancer Center, \\ University of Michigan School of Medicine, \\ Ann Arbor, Michigan 48109, USA
}

Wnts have key roles in many developmental processes, including hair follicle growth and differentiation. Stabilization of $\beta$-catenin is essential in the canonical Wnt signaling pathway. We developed transgenic mice expressing a regulated form of $\beta$-catenin in the skin. Chronic activation of $\beta$-catenin in resting (telogen) hair follicles resulted in changes consistent with induction of an exaggerated, aberrant growth phase (anagen). Transient activation of $\beta$-catenin produced a normal anagen. Our data lend strong support to the notion that a Wnt/ $\beta$-catenin signal operating on hair follicle precursor cells serves as a crucial proximal signal for the telogen-anagen transition.

Received January 17, 2003; revised version accepted April 2, 2003.

Wnt family proteins function in short-range signaling. They regulate cell fate, adhesion, differentiation, proliferation, and motility, and many studies have demonstrated their critical roles in development (for review, see Peifer and Polakis 2000). Mutational defects in Wnt signaling have a major contributing role in a broad spectrum of cancers (Polakis 2000). At present, it appears many Wnts exert their effects, at least in part, through a "canonical" signaling pathway in which stabilization of the $\beta$-catenin protein is essential. Much of the $\beta$-catenin protein in the cell is associated with the cell membrane, where $\beta$-catenin binds to and links E-cadherin to the cytoskeleton through $\beta$-catenin's binding to $\alpha$-catenin. A fraction of the $\beta$-catenin is free in the cytoplasm and/or nucleus. Normally, in the absence of Wnt signals, $\beta$-catenin is bound and negatively regulated by a protein complex that includes the adenomatous polyposis coli (APC) and axin tumor suppressor proteins as well as gly-

[Keywords: $\beta$-catenin; hair follicle; transgenic mouse; anagen; hair cycle] ${ }^{6}$ Present address: Medizinische Klinik II, Klinikum Grosshadern, University of Munich, 81377 Munich, Germany.

Corresponding authors.

${ }^{7}$ E-MAIL dlugosza@umich.edu; FAX (734) 763-4575.

${ }^{8}$ E-MAIL fearon@umich.edu; FAX (734) 647-7979.

Article and publication are at http://www.genesdev.org/cgi/doi/10.1101/ gad.1076103. cogen synthase kinase- $3 \beta$ (GSK-3 $\beta$; for review, see Peifer and Polakis 2000). This complex promotes phosphorylation of $\beta$-catenin at a number of $\mathrm{N}$-terminal serine and threonine residues, and the phosphorylated $\beta$-catenin is ubiquitinated and subsequently degraded by the proteasome.

Binding of Wnts to their cognate frizzled and low-density lipoprotein receptor-related protein receptor complexes on the cell surface leads to inhibition of GSK-3 $\beta$ activity and increased levels of free $\beta$-catenin in the cell (Peifer and Polakis 2000). In cancers, inactivating mutations in the APC or axin proteins or activating mutations affecting $\mathrm{N}$-terminal phosphorylation sites in $\beta$-catenin lead to stabilization of $\beta$-catenin (Polakis 2000). Regardless of whether Wnt signals or mutational defects stabilize $\beta$-catenin, following its accumulation in the cell, $\beta$-catenin can complex in the nucleus with $\mathrm{T}$ cell factor/ lymphoid enhancer factor (TCF/LEF) transcription regulators, leading to activation of TCF-regulated genes (a list of candidate TCF target genes is provided at: http:// www.stanford.edu/ rnusse/wntwindow.html).

Wnt/ $\beta$-catenin signaling has been proposed to function in hair follicle morphogenesis and differentiation (Kishimoto et al. 2000; Fuchs et al. 2001; Millar 2002). Hair follicle morphogenesis is characterized by the downward growth of epithelial hair follicle precursor cells into the embryonic dermis, where follicle precursor cells envelop the mesenchymal dermal papilla to produce the bulb region of the follicle. Cells in the outermost epithelial cell compartment, the outer root sheath (ORS), continue to proliferate and migrate downward to the bulb region throughout the active growth phase of the hair follicle. At the same time, rapidly-proliferating matrix cells in the bulb of mature follicles migrate upward in the central portion of the follicle to give rise to six distinct cell types in the maturing hair shaft and surrounding inner root sheath (IRS). Wnt signaling appears to be involved in patterning in the skin, as mice with a skin-specific deletion of $\beta$-catenin (Huelsken et al. 2001) or mice with constitutive overexpression of an inhibitor of Wnt signaling in skin (Andl et al. 2002) fail to develop hair follicles. Likewise, Lef-1 knockout mice are characterized by arrested development of hair follicles and a complete lack of hair (van Genderen et al. 1994). Conversely, mice expressing a constitutively activated form of $\beta$-catenin lacking critical phosphorylation sites in the $\mathrm{N}$ terminus $(\Delta \mathrm{N} 87 \beta$-catenin) in their skin display evidence of de novo hair follicle morphogenesis in the interfollicular epithelium as they age (Gat et al. 1998). These studies demonstrate a role for Wnt $/ \beta$-catenin signaling during initial development of hair follicles.

Once established, hair follicles undergo a growth cycle consisting of periods of growth (anagen), regression (catagen), and rest (telogen; Muller-Rover et al. 2001). The bulge activation theory proposes the dermal papillae activate anagen by signaling the stem cell compartment of the hair follicle residing in the bulge (for review, see Stenn and Paus 2001). There is evidence consistent with Wnt/ $\beta$-catenin signaling having a role in anagen induction. For example, an increase in $\beta$-galactosidase is seen in the bulge region of the hair follicle at the onset of anagen in TOPgal transgenic mice carrying a TCF/LEF optimal promoter upstream of a $\beta$-galactosidase gene 
(DasGupta and Fuchs 1999). Also, the first postnatal anagen does not occur in mice in which $\beta$-catenin expression is progressively lost in the skin (Huelsken et al. 2001). Finally, Wnts $10 \mathrm{a}$ and $10 \mathrm{~b}$ are expressed in postnatal hair follicles at anagen onset, but not in resting follicles (Reddy et al. 2001). These data are consistent with the view that a Wnt signal activates $\beta$-catenin signaling in the bulge, thereby driving the resting follicle into active growth.

Whereas the data imply a role for $\beta$-catenin in the telogen-anagen transition, no studies have examined the effect of inducible and reversible $\beta$-catenin signaling in the skin, with the goal of modeling the transient activation resulting from effects of canonical Wnt signaling. Therefore, we sought to develop a system in which we could tightly regulate $\beta$-catenin function in the mouse skin. We have shown previously the function of a chimeric $\beta$-catenin protein, in which a full-length $\beta$-catenin polypeptide with a codon 33 activating mutation (serine-totyrosine substitution-S33Y) is fused in-frame to a mutated version of the hormone binding domain of mouse estrogen receptor- $\alpha$ (ER), is rapidly activated by the ligand 4-hydroxytamoxifen (4-OHT) in cultured cells (Kolligs et al. 2002). We expressed the S33Y $\beta$-catenin-ER fusion protein in the skin of transgenic mice using the well-characterized bovine keratin 5 (K5) promoter (Ramirez et al. 1994). We explored effects of chronic and transient activation of $\beta$-catenin signaling in cutaneous keratinoyctes by topical application of 4-OHT. We show here that prolonged activation of $\beta$-catenin signaling results in profound proliferation of the ORS and other epithelial components of the hair follicle. Transient signaling results in activation of a normal anagen phase. These data demonstrate $\beta$-catenin signaling provides a potent growth stimulus for hair follicle progenitor cells and is sufficient, when transiently activated in epithelial hair follicle precursors, to trigger telogen to anagen transition.

\section{Results and Discussion}

\section{Regulation of $\beta$-catenin activity in keratinocytes and transgenic mice}

The generation and use of chimeric proteins containing polypeptide sequences of interest fused to the hormonebinding domain of the mouse ER protein has been a successful strategy for exploring protein function, because the activity of the ER fusion protein can be tightly regulated by 4-OHT, an estrogen agonist/antagonist (Littlewood et al. 1995). As noted above, we generated previously a construct encoding a constitutively active $\beta$-catenin polypeptide (S33Y $\beta$-catenin) fused in-frame to the ER hormone binding domain (S33Y $\beta$-catenin-ER; Kolligs et al. 2002). To investigate $\beta$-catenin function in mouse skin, the S33Y $\beta$-catenin-ER sequences were positioned downstream of the bovine K5 promoter, which directs high levels of transgene expression to stratified squamous epithelium (Ramirez et al. 1994; Fig. 1A). In vitro studies with the human 1811 keratinocyte cell line were pursued to confirm the regulation of the S33Y $\beta$ catenin-ER fusion protein by 4-OHT in keratinocytes. Specifically, 1811 keratinocytes were transfected with expression constructs encoding the S33Y $\beta$-catenin-ER fusion protein, and we assessed the ability of the fusion
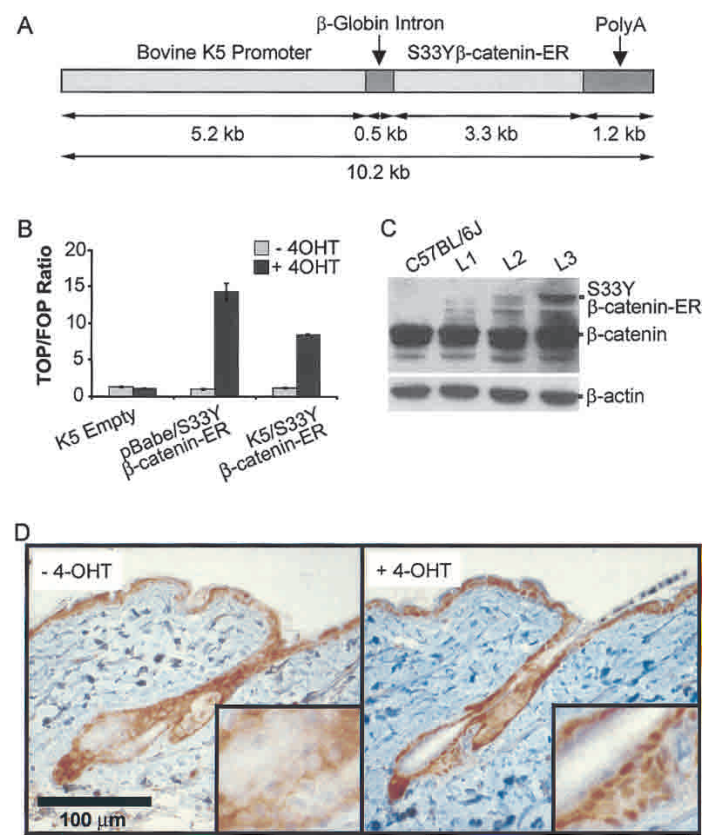

Figure 1. Activation of the K5/S33Y $\beta$-catenin-ER protein by 4-OHT and expression in transgenic mice. (A) Schematic of the K5/ S33Y $\beta$-catenin-ER construct. A cDNA encoding the chimeric protein was subcloned into a bovine K5 expression cassette. (B) Activity of the $\mathrm{K} 5 / \mathrm{S} 33 \mathrm{Y} \beta$-catenin-ER protein is inducible by 4-OHT in 1811 keratinocytes. The 1811 keratinocytes were transfected with an empty K5 cassette, the pBabe/S33Y $\beta$-catenin-ER construct, or the $\mathrm{K} 5 / \mathrm{S} 33 \mathrm{Y} \beta$-catenin-ER construct along with either the TCF-responsive reporter construct TOPFLASH or control FOPFLASH construct. Cells were then treated with either 4-OHT in ethanol, or ethanol alone, and harvested $30 \mathrm{~h}$ later to assess luciferase activity. The assays were performed in duplicate; data are reported as the ratio of relative light units for TOPFLASH:FOPFLASH, normalized for transfection efficiency. $(C)$ Expression of the K5/S33Y $\beta$-catenin-ER fusion protein relative to endogenous $\beta$-catenin in transgenic mouse lines. Protein was isolated from tail skin of F1 mice derived from three independently derived founders and subjected to Western blot analysis with a mouse monoclonal anti- $\beta$-catenin antibody. The blot was reprobed with an anti- $\beta$-actin antibody to verify equal loading and transfer. (D) $\beta$-catenin protein localization in a clipped region of dorsal skin from $\mathrm{K} 5 / \mathrm{S} 33 \mathrm{Y} \beta$-catenin-ER transgenic mice not treated $(-4-\mathrm{OHT})$ or $24 \mathrm{~h}$ after treatment with a single topical dose of $4-\mathrm{OHT}(+4-\mathrm{OHT})$

protein to activate a $\beta$-catenin/TCF-responsive model reporter gene construct in the presence or absence of 4-OHT. One construct used the K5 promoter sequences, whereas the other construct used mouse Moloney leukemia virus long terminal repeat sequences to direct expression (i.e., pBabe). As shown in Figure 1B, the empty K5 expression construct had no demonstrable effects on TCF transcriptional activity, either in the presence or absence of 4-OHT. In contrast, both the pBabe/S33Y $\beta$-catenin-ER and K5/S33Y $\beta$-catenin-ER expression constructs strongly activated TCF transcription in the presence of 4-OHT. In the absence of 4-OHT, the S33Y $\beta$-catenin-ER constructs failed to activate TCF transcription above background levels. Therefore, the function of the S33Y $\beta$-catenin-ER fusion protein is tightly regulated by 4-OHT in keratinocytes.

After demonstrating 4-OHT-regulated activity of the fusion protein in the keratinocyte cell line, we generated transgenic mice carrying the K5/S33Y $\beta$-catenin-ER construct. Potential K5/S33Y $\beta$-catenin-ER founders were 
screened for the transgene by PCR, and three transgenic lines were selected for further studies based on Western blot data showing differing levels of S33Y $\beta$-catenin-ER fusion protein expression in the skin of the mice (Fig. 1C). F1 mice were generated by backcross of the founder mice onto a C57BL/6J background. The majority of the studies described here used F3 or later generations of mice generated from the L2 line with moderate levels of transgene expression. Expression of the chimeric S33Y $\beta$ catenin-ER protein in the skin of transgenic mice appeared to be at levels well below those of the endogenous $\beta$-catenin protein (Fig. 1C). Within $24 \mathrm{~h}$ after a single topical application of $4-\mathrm{OHT}$ to the skin of $\mathrm{K} 5 / \mathrm{S} 33 \mathrm{Y} \beta$ catenin-ER transgenic mice, strong nuclear staining for $\beta$-catenin protein was seen in nuclei of cells in both the interfollicular epidermis and the lower follicle (Fig. 1D).

\section{Chronic activation of $\beta$-catenin function in follicular epithelium induces proliferation and alters differentiation}

Preliminary experiments focused on effects of chronic activation of $\beta$-catenin function in the skin. Mice derived from the L2 line were subjected to topical treatment with 4-OHT on a shaved region of dorsal skin. As $\beta$-catenin signaling has been implicated previously in several aspects of hair growth and differentiation, we took care to treat mice during a resting phase in the hair growth cycle. Mice are known to undergo two sequential waves of hair growth before entering a prolonged telogen phase by seven weeks of age (Muller-Rover et al. 2001), so we selected day 50 for initiation of 4-OHT treatment to ensure control follicles would be in telogen for at least three additional weeks. Both transgenic mice and wildtype littermate controls were treated daily with 4-OHT for $1,3,7$, and $14 \mathrm{~d}$. No demonstrable effects were observed in the skin of wild-type mice treated with 4-OHT (Fig. 2) or transgenic mice treated with ethanol alone (data not shown). In contrast, dramatic changes were seen in the transgenic mice treated with 4-OHT. Histological studies revealed obvious changes following $3 \mathrm{~d}$ of treatment, with an increased number of ORS keratinocytes readily apparent (Fig. 2). Following $7 \mathrm{~d}$ of $4-\mathrm{OHT}$ treatment, hair follicles were hyperplastic with features

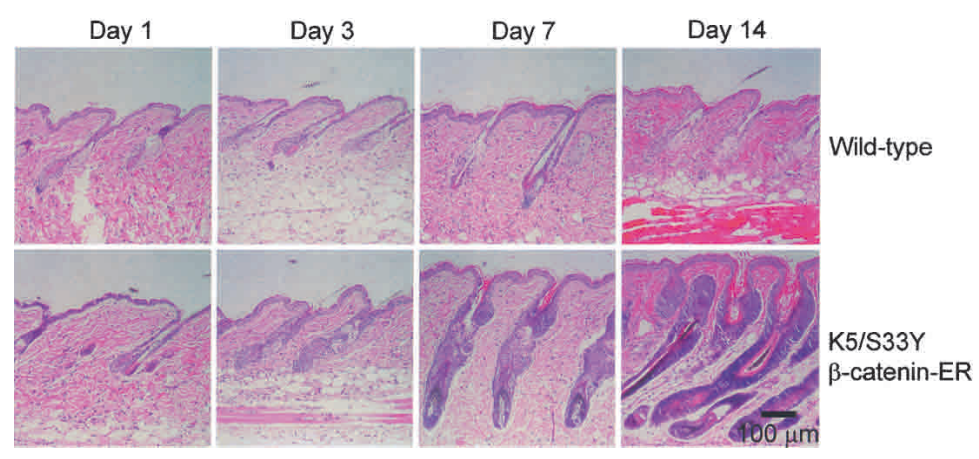

Figure 2. Growth and differentiation of the hair follicle in K5/S33Y $\beta$-cateninER mice treated daily with 4-OHT. A region of dorsal hair was clipped on both transgenic and wild-type littermates and the skin area was treated daily with 4-OHT in ethanol. Parasagittal sections of skin were taken at time points following initiation of treatment and stained with hematoxylin and eosin. Hair follicles in wild-type mice remained in the resting phase (telogen) throughout the experiment; growth and differentiation of transgenic hair follicles was dramatically stimulated. resembling those normally seen in hair follicles in anagen phase. In addition to marked expansion of ORS cells, the hair follicles had grown into deeper levels of the dermis; compartmentalization of epithelial cell types was evident; and melanin was present in the hair bulb, which contained a normal-appearing dermal papilla. Whereas most of the histological features resemble those in anagen phase (Muller-Rover et al. 2001), the overall size of the follicles appeared to be greater, largely attributable to increased numbers of ORS cells (Fig. 2). By day 14, follicles in the 4-OHT-treated transgenic mice were even more hyperplastic, composed largely of basophilic cells with scant cytoplasm. Prominent hyperkeratosis of the epithelium at the top of the hair follicles was also seen (Fig. 2). In the transgenic mice subjected to chronic 4-OHT treatment, hair growth was not evident despite histological features suggesting hair growth might be seen. We speculate the hair was lost as a result of the abnormal follicular epithelial proliferation and/or secondary alterations in hair shaft differentiation and assembly induced by chronic activation of $\beta$-catenin signaling function. It is worth noting that antagonism of estrogen receptor signaling by the compound ICI-182780 has been shown to promote anagen onset in mice (Oh and Smart 1996). However, our data are consistent with a subsequent study (Chanda et al. 2000), which demonstrated that topical treatment with 4-OHT has no significant effect on progression to anagen.

Hair follicle growth and differentiation were assessed further in the transgenic mice subjected to chronic 4-OHT treatment through studies of BrdU incorporation and analysis of expression markers that distinguish cell compartments in the follicle (Fig. 3). Parasagittal skin sections were examined from wild-type and transgenic mice treated with 4-OHT for $14 \mathrm{~d}$. Skin sections from wild-type mice in spontaneous anagen were also examined. A dramatic increase in BrdU-labeling was detected throughout the ORS in the transgenic mice treated with 4-OHT for $14 \mathrm{~d}$ (Fig. 3a,b). In contrast, in wild-type hair follicles in anagen, proliferation was largely limited to the hair bulb (data not shown) with occasional BrdUlabeled cells detected in the ORS (Fig. 3c). Keratin 17 (K17) expression is seen predominantly in ORS cells, and an expansion in the population of K17-expressing cells was seen following $14 \mathrm{~d}$ of $4-\mathrm{OHT}$ treatment of the K5/S33Y 3 -catenin-ER mice (Fig. 3d-f). An increase in keratin $6(\mathrm{~K} 6)$ expression, which localizes to the inner layer of the ORS, was also noted in the transgenic mice (Fig. 3g-i). Interestingly, there was little proliferation of the basal cell layer of the epidermis despite high levels of K5directed transgene expression in that compartment (Figs. 1D, 3j-1). This likely reflects the absence of TCF/LEF factors in the basal cell layer (Gat et al. 1998). The pattern of expression for the IRS marker trichohyalin was also abnormal in the transgenic mice. Whereas trichohyalin expression in normal anagen follicles is detected in the hair bulb and extends up to about the level of the arrector pili muscle, chronic activation of $\beta$-catenin signaling led to more diffuse expression of trichohyalin in transgenic mice (Fig. 3mo). Despite striking alterations in the upper part of the follicle, the lower portion appeared to differentiate quite normally, as shown by staining for hair keratin (Fig. 3p-r) and dermal papillae 


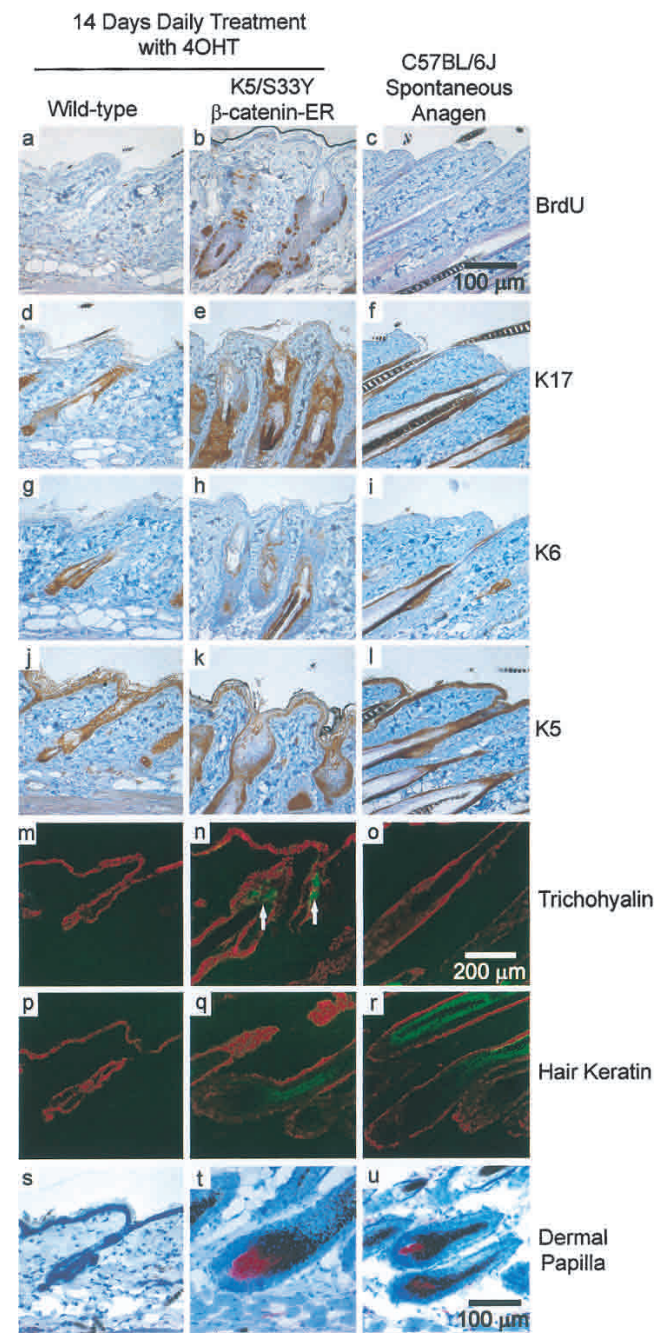

Figure 3. Altered expression of hair follicle markers in K5/S33Yßcatenin-ER mice. Immunohistochemistry and immunofluorescence were performed on parasagittal sections of skin from both wild-type and $\mathrm{K} 5 / \mathrm{S} 33 \mathrm{Y} \beta$-catenin-ER mice in addition to a normal, spontaneous anagen cycle in a C57BL/6J mouse. The markers used were as follows: $\operatorname{BrdU}(a-c), \mathrm{K} 17(d-f), \mathrm{K} 6(g-i), \mathrm{K} 5(j-1)$, trichohyalin $(m-O)$, hair keratin $(p-r)$, and alkaline phosphatase staining for dermal papillae $(s-u)$. White arrows highlight ectopic trichohyalin staining in $n$. Bars: $a-l, s-u, 100 \mu \mathrm{m} ; m-r, 200 \mu \mathrm{m}$.

(Fig. 3s-u). Because the K5 promoter is active in the entire outer root sheath, the results suggest proliferative responses to the S33Y $\beta$-catenin mutant may vary depending on location, perhaps because of expression of different complements of TCF transcription factors (DasGupta and Fuchs 1999; Merrill et al. 2001). Chronic activation of $\beta$-catenin signaling in keratinocytes therefore drives both exaggerated proliferation and terminal differentiation of several epithelial cell types in the hair follicle.

Mice treated topically with 4-OHT for a longer time periods exhibited changes similar to, but more severe, than those seen after $14 \mathrm{~d}$ of treatment (data not shown). The epithelial architecture in the skin was quite abnormal, but the changes appeared more consistent with a hyperplastic process involving several cell types rather than frank neoplasia. We were unable to subject transgenic mice to topical 4-OHT treatment for $>25 \mathrm{~d}$, be- cause the mice exhibited signs of distress and often became moribund. These findings may be attributable to systemic distribution of 4-OHT in chronically treated mice and activation of $\mathrm{K} 5 / \mathrm{S} 33 \mathrm{Y} \beta$-catenin transgene signaling in esophagus and forestomach (D. Van Mater and E.R. Fearon, unpubl.). Of note, mice derived from the L3 transgenic line with high levels of S33Y $\beta$-catenin-ER expression died after roughly $7 \mathrm{~d}$ of topical 4-OHT treatment because of bleeding in the upper gastrointestinal tract (data not shown).

\section{Transient $\beta$-catenin activation in telogen follicles induces a normal anagen}

Given the proliferative response of hair follicles in transgenic mice chronically treated with 4-OHT and published data suggesting a role for Wnt signaling in initiating anagen, we sought to assess the consequences of transient $\beta$-catenin activation in resting (telogen) hair follicles. Transgenic and wild-type mice whose hair follicles were in telogen were treated with a single topical dose of 4-OHT or ethanol alone. The mice were then followed for several weeks. Remarkably, $\sim 15 \mathrm{~d}$ after a single 4-OHT treatment, grossly normal hair growth was observed in the clipped and 4-OHT-exposed region of the transgenic mice (Fig. 4A). In transgenic mice treated with ethanol alone or in wild-type littermates exposed to a single topical dose of 4-OHT or ethanol alone, no hair growth was seen (Fig. 4A).

Histological analyses were pursued on skin specimens obtained at various time points from transgenic and wild-type mice following a single topical dose of 4-OHT. Of note, a single 4-OHT treatment led to a synchronized pattern of normal-appearing follicle growth in the exposed skin, indistinguishable from follicle growth seen in depilation-induced anagen (Muller-Rover et al. 2001; Fig. 4B). The follicles progressed through anagen phase and then entered catagen and telogen at the expected times, between days 19-22. The changes seen in the follicles from transgenic mice exposed to a single 4-OHT treatment mirror the changes seen in follicles during their normal progression through the hair cycle (MullerRover et al. 2001). BrdU-labeling was localized largely to the matrix of the growing follicle, and immunohistochemistry studies with the panel of hair follicle markers described above yielded the expected pattern of expression for normal anagen follicles (data not shown). The induction of an apparently normal anagen following a single 4-OHT treatment was also seen in the L3 transgenic line (data not shown).

There are several possible explanations for phenotypic differences between the previously reported K14/ $\Delta$ N87 $\beta$ catenin mouse (Gat et al. 1998) and our K5/S33Y $\beta$ catenin-ER mouse. Amino acids in the $\beta$-catenin $N$ terminus appear important for $\beta$-catenin transcriptional regulation (Kolligs et al. 1999), and differing transcription activities may lead to differing functions in vivo. In contrast to the $\mathrm{N}$-terminal deleted $\beta$-catenin protein in the Gat et al. (1998) model, our model uses an intact $\beta$-catenin protein with a stabilizing point mutation. Yet another variable contributing to differing results seen with the two models might be the possibility that our model allowed a higher degree of $\beta$-catenin signaling activity in the keratinocyte. The S33Y $\beta$-catenin-ER protein is inactive unless $4-\mathrm{OHT}$ is present, whereas the $\mathrm{K} 14 / \Delta \mathrm{N} 87 \beta$-catenin transgenic mouse expresses a con- 
A

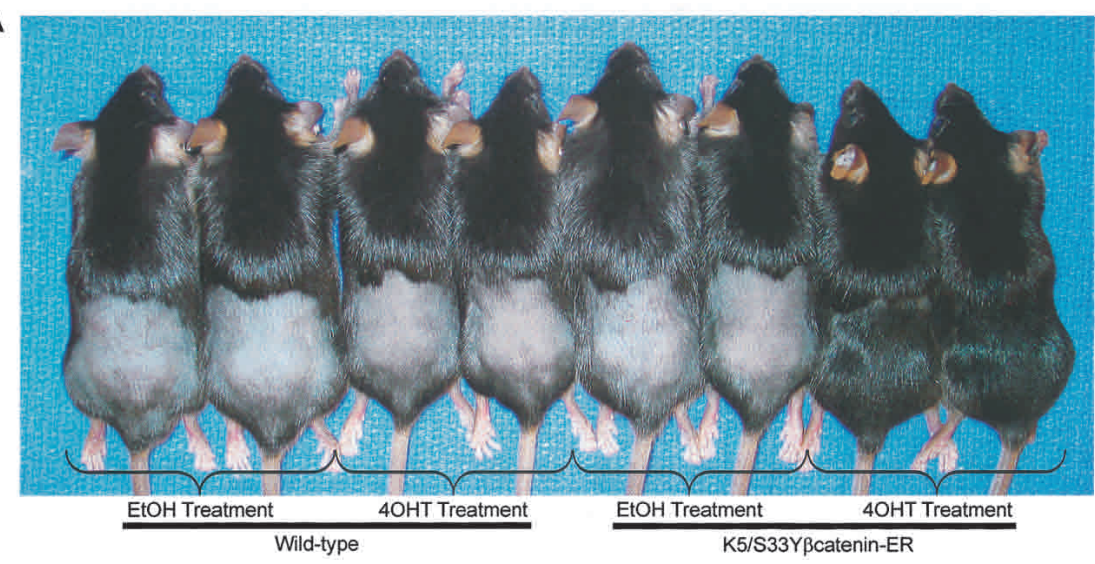

B

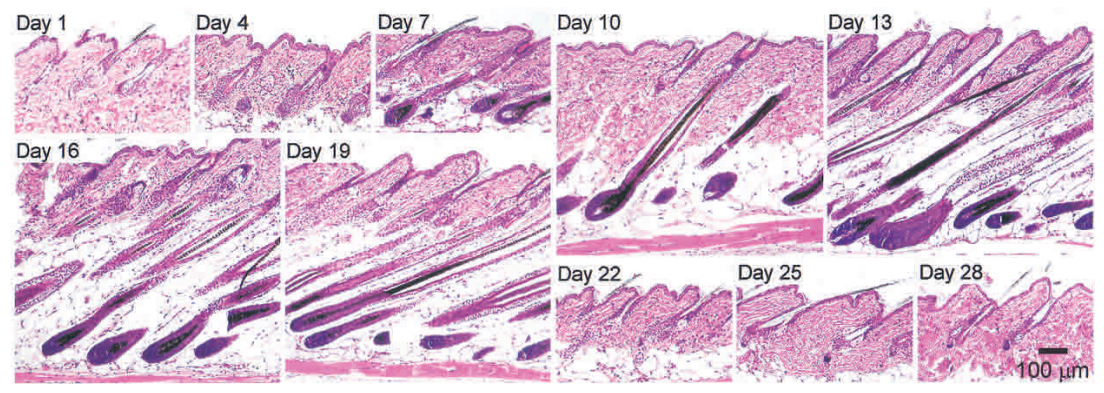

Figure 4. Transient treatment with 4-OHT is sufficient for normal anagen induction in K5/ S33Y $\beta$-catenin-ER mice. (A) Hair growth in K5/S33Y $\beta$-catenin-ER mice following a single topical treatment with 4-OHT. The experiment was performed on L2 transgenic mice obtained following backcrossing to C57BL/6J mice for six generations. Hair on wild-type and transgenic littermates was clipped and the skin region treated with a single dose of 4-OHT in ethanol or ethanol alone. Hair growth at $17 \mathrm{~d}$ after 4-OHT treatment is shown. (B) Histology of hair follicles in K5/S33Y $\beta$-catenin-ER mice over time after a single treatment with 4-OHT. A cohort of transgenic mice was clipped and treated with 4-OHT and followed for a period of 28 d. Parasagittal skin sections obtained at various times after 4-OHT treatment were stained with hematoxylin and eosin. Bar, $100 \mu \mathrm{m}$.

stitutively active $\beta$-catenin protein. As such, there may have been some selection in the work of Gat et al. (1998) for mice expressing relatively low levels of the K14/ $\Delta \mathrm{N} 87 \beta$-catenin transgene, because high activity during much of skin development might be deleterious. Consistent with this view, whereas hair follicles in the K14/ $\Delta \mathrm{N} 87 \beta$-catenin mice had an essentially normal morphology, we saw an exaggerated and aberrant anagen after chronic activation of $\beta$-catenin signaling in our transgenic mice.

In summary, we have described here a transgenic mouse model permitting transient activation of $\beta$-catenin signaling in the skin by topical treatment with the ligand 4-OHT. Chronic activation of $\beta$-catenin signaling during telogen phase resulted in profound proliferation of the ORS, growth of the follicle into deeper levels of the dermis, melanogenesis, and enhanced production of several differentiated epithelial cell types. The features observed following chronic activation of $\beta$-catenin during telogen were consistent with induction of an exaggerated, aberrant anagen phase in the follicular epithelium. Remarkably, a single treatment with 4-OHT resulted in activation of an apparently normal anagen in resting hair follicles. Therefore, our findings imply that carefully controlled activation of $\beta$-catenin signaling is not only necessary (Huelsken et al. 2001; Andl et al. 2002), but also likely sufficient, for anagen initiation.
The data offer strong support for the notion that a transient Wnt signal provides the crucial initial stimulus for the start of a new hair growth cycle, by activating $\beta$-catenin and TCF-regulated gene transcription at the telogen-anagen transition in epithelial hair follicle precursors.

\section{Materials and methods}

K5/S33Y $\beta$-catenin-ER expression construct The generation of the S33Y $\beta$-catenin-ER construct in the pBabePuro vector has been described previously (Kolligs et al. 2002). The K5 expression construct was obtained from José Jorcano (CIEMAT). It consists of $5.2 \mathrm{~kb}$ of the bovine K5 upstream region, a rabbit $\beta$-globin intron, and two copies of the SV40 polyadenylation sequence (Ramirez et al. 1994). The S33Y $\beta$ cat-ER construct was excised from the $\mathrm{pBa}$ bePuro vector with BamHI and MluI, bluntended with Klenow fragment, and cloned into the blunt-ended SnaBI site of the bovine K5 expression cassette.

\section{Cell culture and reporter assays}

The human 1811 keratinocyte cell line was provided by K. Cho (University of Michigan) and propagated in KGM medium (Clonetics). For reporter assays, $3 \times 10^{5}$ cells were seeded in 35 $\mathrm{mm}$ dishes $12 \mathrm{~h}$ before transfection. Cells were transfected with $4 \mu \mathrm{L}$ FuGENE6 (Boehringer Mannheim), $1 \mu \mathrm{g}$ of the S33Y $\beta$-catenin-ER construct, $0.5 \mu \mathrm{g}$ of pTOPFLASH or pFOPFLASH (provided by B. Vogelstein, Johns Hopkins University), and $0.5 \mu \mathrm{g}$ of pCH110. After $24 \mathrm{~h}, 500$ nM 4-OHT (Sigma; prepared in a stock concentration of $100 \mu \mathrm{M}$ in $100 \%$ ethanol) or ethanol alone was added to the cells. The cells were harvested $30 \mathrm{~h}$ after treatment using reporter lysis buffer (Promega). Luciferase activity was measured with a luminometer and $\beta$-galactosidase activities were determined by standard methods to control for transfection efficiency.

Generation of transgenic mice

Transgenic mice were generated by the University of Michigan Transgenic Animal Model Core. The transgene expression construct was linearized with BssHII, purified, and injected into the male pronucleus of (C57BL/6 X SJL)F2 mouse eggs, which were then surgically transferred to pseudopregnant foster mice. Offspring were screened for the presence of the transgene by PCR on mouse tail DNA using primers specific for the transgene sequence. Three independent founder lines were generated and transgenic mice were backcrossed to C57BL/6J mice (Jackson Laboratory) for at least three generations. To verify transgene expression, a section of mouse tail was obtained and homogenized in lysis buffer $(50 \mathrm{mM}$ Tris at pH 7.5, 120 mM NaCl, 1 mM EDTA, 1\% NP-40, 10\% glycerol, Roche Complete Mini protease inhibitor tablet). Western blotting was performed on $15 \mu \mathrm{g}$ total protein using mouse monoclonal anti- $\beta$-catenin (BD Transduction Laboratories) and anti- $\beta$-actin (Sigma) antibodies at a 1:5000 dilution.

Administration of 4-OHT and preparation of sections for histology Hair in a roughly $4-\mathrm{cm}^{2}$ region of dorsal skin from the mice was clipped to $0.1 \mathrm{~mm}$, and the clipped area was treated with $0.5 \mathrm{mg}$ of 4-OHT (Sigma) dissolved in $100 \mu \mathrm{L}$ ethanol once per day for various time courses. One hour before euthanasia, mice were injected with an intraperitoneal injection of $100 \mu \mathrm{g}$ BrdU per gram body weight. Skin samples were obtained from transgenic mice and wild-type littermates, fixed overnight in $10 \%$ neutral buffered formalin at $4{ }^{\circ} \mathrm{C}$, and then transferred to $70 \%$ ethanol before being processed and embedded in paraffin. Parasagittal sections $(5 \mu \mathrm{m})$ of dorsal skin were then stained with hematoxylin and eosin. 
Immunohistochemistry

Unstained sections were taken from the paraffin blocks described above. The slides were baked overnight at $60^{\circ} \mathrm{C}$ and then deparaffinized and rehydrated. Endogenous peroxidase was quenched with $0.3 \% \mathrm{H}_{2} \mathrm{O}_{2}$ in methanol. Antigen retrieval was then performed in $1 \mathrm{X}$ Antigen Retrieval Citra (BioGenex), according to the manufacturer's recommendations. Primary antibodies were used at the following dilutions with the Mouse on Mouse (M.O.M.; Vector Laboratories) or Rabbit IgG Vectastain ABC kit (Vector Laboratories): mouse monclonal anti-BrdU (Zymed; 1:200) and anti- $\beta$-catenin (BD Transduction Laboratories; $1: 250)$ and rabbit polyclonal anti-K5 (Covance; 1:1000), K6 (Covance; 1:500), and K17 (provided by Pierre Coulombe, Johns Hopkins University; 1:1000). The M.O.M. biotinylated anti-mouse IgG or anti-rabbit IgG reagent was then added to the slide, followed by the avidin-biotinylated peroxidase complex. Staining was performed with 3,3'-diaminobenzidine (DAB; Vector Laboratories) as explained in the manufacturer's protocol. Sections were counterstained with hematoxylin and mounted using Cytoseal 60 (Stephens Scientific).

\section{Immunofluorescence}

Frozen sections $(10 \mu \mathrm{m})$ were taken of skin samples and warmed to room temperature. They were then fixed in ice-cold acetone for $10 \mathrm{~min}$ and air-dried. Nonspecific binding was prevented by incubation with the blocking reagent included in the Mouse on Mouse kit (M.O.M.; Vector Laboratories), followed by incubation with mouse monoclonal antibodies AE15 (1:50) to detect trichohyalin or AE13 (1:150) to detect hair keratins, both kindly provided by Henry Sun (New York University), and rabbit polyclonal anti-K5 (1:1000). The secondary antibodies (Jackson ImmunoResearch) were FITC-conjugated goat anti-mouse IgG (1:75) and Texas Red-conjugated goat anti-rabbit IgG (1:50).

Staining for dermal papillae

To detect endogenous alkaline phosphatase activity in dermal papillae, frozen sections $(10 \mu \mathrm{m})$ were treated with the Vector Red Alkaline Phosphatase Substrate Kit I (Vector Laboratories) according to the manufacturer's recommendations, followed by hematoxylin counterstaining.

\section{Acknowledgments}

This work was supported by CA85463, CA87837, CA46592, and T32GM07863. We thank Drs. Jose Jorcano, Pierre Coulombe, Bert Vogelstein, Kathleen Cho, and Henry Sun for providing reagents, and the University of Michigan Transgenic Animal Model Core for support of the transgenic work.

The publication costs of this article were defrayed in part by payment of page charges. This article must therefore be hereby marked "advertisement" in accordance with 18 USC section 1734 solely to indicate this fact.

\section{References}

Andl, T., Reddy, S.T., Gaddapara, T., and Millar, S.E. 2002. WNT signals are required for the initiation of hair follicle development. Dev. Cell. 2: 643-653.

Chanda, S., Robinette, C.L., Couse, J.F., Smart, R.C. 2000. 17ß-estradiol and ICI-182780 regulate the hair follicle cycle in mice through an estrogen receptor- $\alpha$ pathway. Am. J. Physiol. Endocrinol. Metab. 278: E202-E210.

DasGupta, R. and Fuchs, E. 1999. Multiple roles for activated LEF/TCF transcription complexes during hair follicle development and differentiation. Development 126: 4557-4568.

Fuchs, E., Merrill, B.J., Jamora, C., and DasGupta, R. 2001. At the roots of a never-ending cycle. Dev. Cell 1: 13-25.

Gat, U., DasGupta, R., Degenstein, L., and Fuchs, E. 1998. De Novo hair follicle morphogenesis and hair tumors in mice expressing a truncated beta-catenin in skin. Cell 95: 605-614.

Huelsken, J., Vogel, R., Erdmann, B., Cotsarelis, G., and Birchmeier, W. 2001. Beta-Catenin controls hair follicle morphogenesis and stem cell differentiation in the skin. Cell 105: 533-545.

Kishimoto, J., Burgeson, R.E., and Morgan, B.A. 2000. Wnt signaling maintains the hair-inducing activity of the dermal papilla. Genes \& Dev. 14: 1181-1185.

Kolligs, F.T., Hu, G., Dang, C.V., and Fearon, E.R. 1999. Neoplastic transformation of $\mathrm{RK} 3 \mathrm{E}$ by mutant beta-catenin requires deregulation of
Tcf/Lef transcription but not activation of c-myc expression. Mol. Cell. Biol. 19: 5696-5706.

Kolligs, F.T., Nieman, M.T., Winer, I., Hu, G., Van Mater, D., Feng, Y., Smith, I.M., Wu, R., Zhai, Y., Cho, K.R., et al. 2002. ITF-2, a downstream target of the Wnt/TCF pathway, is activated in human cancers with beta-catenin defects and promotes neoplastic transformation. Cancer Cell 1: 145-155.

Littlewood, T.D., Hancock, D.C., Danielian, P.S., Parker, M.G., and Evan, G.I. 1995. A modified oestrogen receptor ligand-binding domain as an improved switch for the regulation of heterologous proteins. Nucleic Acids Res. 23: 1686-1690.

Merrill, B.J., Gat, U., DasGupta, R., and Fuchs, E. 2001. Tcf3 and Lef1 regulate lineage differentiation of multipotent stem cells in skin. Genes \& Dev. 15: 1688-1705.

Millar, S.E. 2002. Molecular mechanisms regulating hair follicle development. J. Invest. Dermatol. 118: 216-225.

Muller-Rover, S., Handjiski, B., van der Veen, C., Eichmuller, S., Foitzik, K., McKay, I.A., Stenn, K.S., and Paus, R. 2001. A comprehensive guide for the accurate classification of murine hair follicles in distinct hair cycle stages. J. Invest. Dermatol. 117: 3-15.

Oh, H.S. and Smart, R.C. 1996. An estrogen receptor pathway regulates the telogen-anagen hair follicle transition and influences epidermal cell proliferation. Proc. Natl. Acad. Sci. 93: 12525-12530.

Peifer, M. and Polakis, P. 2000. Wnt signaling in oncogenesis and embryogenesis-a look outside the nucleus. Science 287: 1606-1609.

Polakis, P. 2000. Wnt signaling and cancer. Genes \& Dev. 14: 1837-1851.

Ramirez, A., Bravo, A., Jorcano, J.L., and Vidal, M. 1994. Sequences 5' of the bovine keratin 5 gene direct tissue- and cell-type-specific expression of a lacZ gene in the adult and during development. Differentiation 58: 53-64.

Reddy, S., Andl, T., Bagasra, A., Lu, M.M., Epstein, D.J., Morrisey, E.E., and Millar, S.E. 2001. Characterization of Wnt gene expression in developing and postnatal hair follicles and identification of Wnt5a as a target of Sonic hedgehog in hair follicle morphogenesis. Mech. Dev. 107: 69-82.

Stenn, K.S. and Paus, R. 2001. Controls of hair follicle cycling. Physiol. Rev. 81: 449-494.

van Genderen, C., Okamura, R.M., Farinas, I., Quo, R.G., Parslow, T.G., Bruhn, L., and Grosschedl, R. 1994. Development of several organs that require inductive epithelial-mesenchymal interactions is impaired in LEF-1-deficient mice. Genes \& Dev. 8: 2691-2703. 


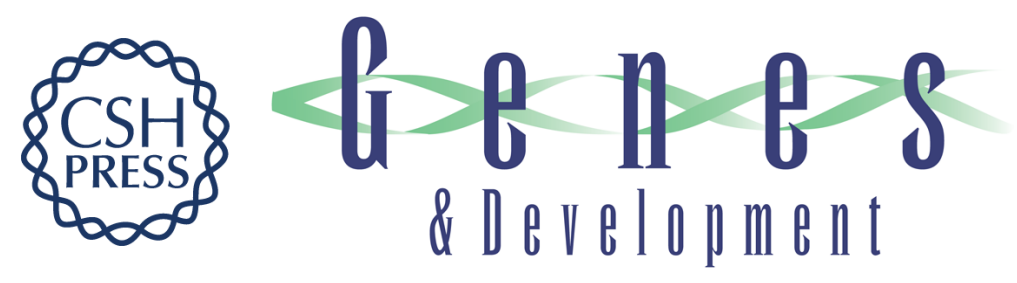

\section{Transient activation of $\beta$-catenin signaling in cutaneous keratinocytes is sufficient to trigger the active growth phase of the hair cycle in mice}

David Van Mater, Frank T. Kolligs, Andrzej A. Dlugosz, et al.

Genes Dev. 2003, 17:

Access the most recent version at doi:10.1101/gad.1076103

References This article cites 20 articles, 8 of which can be accessed free at:

http://genesdev.cshlp.org/content/17/10/1219.full.html\#ref-list-1

License

Email Alerting

Receive free email alerts when new articles cite this article - sign up in the box at the top

Service right corner of the article or click here.

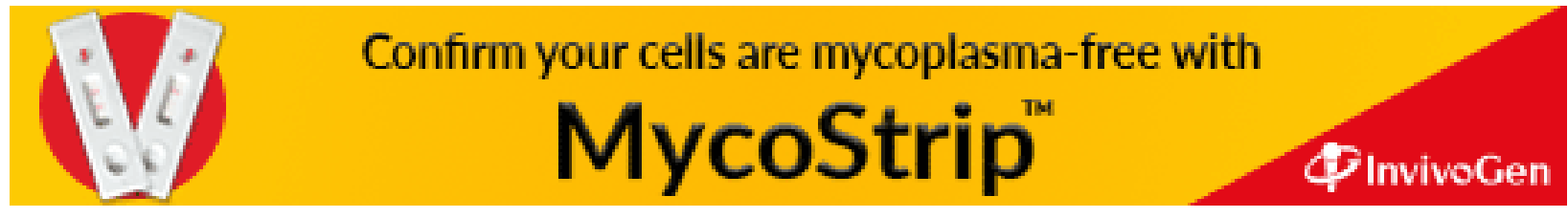

